\title{
Developing Coalitions by Pairwise Comparisons: a Preliminary Study
}

\author{
Waldemar W. Koczkodaj \\ Laurentian University \\ in Sudbury \\ 935 Ramsey Lk Rd, ON P3E 2C6, Canada \\ E-mail: wkoczkodaj@cs.laurentian.ca
}

\author{
Anna Tatarczak \\ Maria Curie-Skłodowska University \\ in Lublin \\ Plac Marii Curie-Skłodowskiej 5, 20-031 Lublin, Poland \\ E-mail: anna.tatarczak@poczta.umcs.pl
}

\begin{abstract}
In all industries, competition between business organizations is vital to utilize collaborative logistics for planning, forecasting and efficient customer response to optimize the supply chain. Consequently, numerous business organizations build coalitions among themselves making their partnerships more effective.

The main goal of this study is to investigate how pairwise comparisons can identify near optimal coalition (related to collective intelligence in terms of computer science) for a group of independent business organizations.

Case studies are used to demonstrate the utility of the framework.

Index Terms-Collective intelligence, horizontal logistics collaboration, coalition, pairwise comparison, consistency analysis, expert opinion, knowledge management, business process.
\end{abstract}

\section{INTRODUCTION}

C OLLABORATION mechanism, widely studied in logistics [1], [4], [10], [13], [16], [27], economics [5], [17], [24], [25], [30] and collective intelligence [33], [34], [38], [41], has specified two important issues: alliance formation and gain allocation.

Most models study the process of coalition formation in which all players contemplate forming one big coalition e.g. [37]. However, in many business settings the objective of development cooperation is obtaining the optimal alliance structure. In order to efficiently achieve individual goals and rewards through cooperation, a coalition may not necessary contain all possible collaborations. In realistic scenario, the coalition formation may be required to deal with both possible sub-groups of participants and individual preferences of each potential collaborator. These sub-groups are translated into number of sub-coalitions among independent firms. Finally, these models should reflect the fact that players must take their decision-making problems about in which coalitions they want to be. In particulary, some coalition structure may be more preferable to others. To the best of our knowledge, there is no study that jointly considers these two research problems. For it, we adopt pairwise comparisons (PC) to develop a model of collaboration mechanism.

The paper is structured as follows. Section II is devoted to comprehensive introduction to PC. Section III-A reviews the comprehensive literature concerning the problems of alliance formation in logistics cases. In Section III-B we explain why enterprisers need to collaborate horizontally in logistics, as well as we introduce an alliance formation model among independent companies by PC. Next, in Section IV the method is illustrated by numerical example taken from logistics cases. The last Section concludes the paper, indicating the limits and a list of important directions for further research. Finally, this study is a continuation of what was previously presented at FedCSIS in [18], [6], [2].

\section{PRELIMINARIES - PAIRWISE COMPARISONS}

Pairwise comparisons may be one of the oldest methods used in science, where we compare entities $E_{i}$ in pairs when there is no unit of measure in use. In fact, most units are well defined for what we perceive to be "objective" entities. We can effectively measure: distance, weight, temperature, or time. From a mathematical point of view, pairwise comparisons (PC) create a PC matrix (say, $M$ ) of values $\left(m_{i j}\right)$ of the $i$-th entity compared with the $j$-th entity. A small rating scale $[1 / c, c]$ is used for $i$ to $j$ comparisons where $c>1$ is a not-toolarge real number (where $c$ is usually 3 to 5 in most practical applications). It is frequently assumed that all the values $m_{i j}$ on the main diagonal are 1 (the case of $E_{i}$ compared with $E_{i}$ and that $M$ is reciprocal: $m_{i j}=1 / m_{j i}$ for every $i, j=$ $1, \ldots, n$, since $x=1 /(1 / x)$.

A pioneer of using PC method for elections was Llull in 13th century. Independently, Condorcet [7] used the pairwise comparisons in his publication of 1785 in the context of counting political ballots. In 1860, however, Fechner used this method in [14]. Thurstone [36] described pairwise comparisons method as the Law of Comparative Judgments in [36]. In 1977, Saaty [32] introduced a hierarchy instrumental for practical applications. However, shortcomings of this work have been criticized in [21].

The usefulness of pairwise comparisons approach, as well as reference to Llull were evidenced in one of the flagship ACM publications [12]. Furthermore, Professor Kenneth J. Arrow, the Nobel prize winner, has used "pair" 24 times in his seminal work [3].

We assume that $M$ is a reciprocal PC matrix over $R^{+}$, and $M$ is of the form: 


$$
M=\left[\begin{array}{cccc}
1 & m_{12} & \cdots & m_{1 n} \\
\frac{1}{m_{12}} & 1 & \cdots & m_{2 n} \\
\vdots & \vdots & \vdots & \vdots \\
\frac{1}{m_{1 n}} & \frac{1}{m_{2 n}} & \cdots & 1
\end{array}\right]
$$

\section{COALition Formation In Horizontal Logistics COLLABORATION}

\section{A. Literature review}

In the past few decades, great attention has been placed on the logistics collaborations, which is concerned to be attained when two or more business organizations enter into a partnership for the purpose of improving the goals of supply chain in an effective and efficient way. Logistics collaborations are categorized as vertical and horizontal.

In this paper, we focus our attention on horizontal cooperation in logistics. It is defined as collaborations between companies that occurs on the same level of the supply chain [10] (e.g. collaboration among suppliers). The primary objective of the horizontal cooperation for each members is reduction of the costs. At the same time, coalition members can also achieve efficiency improvement and better customer service. Based on the research by Cruijssen [9], motives for horizontal cooperation can be categorized as listed in Table I.

The theory of coalition formation have traditionally been analyzed based on cooperative game theory. This popular approach was rewarded when L.S. Shapley received the Nobel Memorial Price in Economics Sciences 2012 together with A. E. Roth. Different cases of coalition formation and cost allocation methods are reported in the recent literature. However, the most popular are five types: transportation planning, traveling salesman problem, vehicle routing, joint distribution, and inventory related problems.

The horizontal collaboration in logistics is profitable, but the categories of impediments were also defined. They are: partner selection, negotiation and coordination, information and communication technology, determining and dividing the gains [9]. Taken into account the main barriers to collaboration, which are the problems of partner selection and communication technology factors we proposed a heuristic model on coalition determination in Section III-B through the application of PC.

Given this background, coalition formation among independent firms has received a considerable amount of attention in recent research, and has proven to be adaptable in most practical cases.

\section{B. Model of study}

Game theory [26] provides a good notion for several concepts which are useful in coalition formation e.g. players, coalition, stability, super-additivity. Let $N$ be a finite set of players and $X$ a finite set of states. For convenience, the players are numbered such that $N=\{1,2, \ldots, n\}$. A coalition is a nonempty subset $S$ of $N$. If two players do not cooperate, they belong to different coalitions. The grand coalition refers to $S=N$

For the further discussion, we assume that the set of players is finite equal $N=3$. Particulary, this study examines the subject of alliance formation among $n(n \geq 3)$ independent firms that have a great potential to create synergies. In particular, we consider a group of three business organizations: $X_{1}, X_{2}, X_{3}$. In order to save on transportation costs, business organizations want to collaborate with each other, but usually, players do not know in which combination. Some strategic alliances and alliance partners can be more preferable and more probable than others. For $n=3$ there are four possible situation (which are non-empty and non-singletons), namely

- $X_{1}$ can create a coalition with $X_{2}$,

- $X_{1}$ can create a coalition with $X_{3}$,

- $X_{2}$ can create a coalition with $X_{3}$,

- grand coalition $X_{1}, X_{2}, X_{3}$ could be formed.

When all business organizations create a grand coalition, it is the most concerning alliance formation problem when the collaboration is super-additive. It is addressed in [28], [29], [23], [22], [15], [11]. The super-additivity means that whatever two separate coalitions creating union get at least as much as they get independently. Under these circumstances, it may be expected to form a grand coalition. Contrary to many complex logistics issues (as it is in the case of our model), super-additivity is too exigent.

Through coalition formation process, the cost reduction could be achieved by applying pooling strategies on logistics planning and optimization, which is defined as common usage logistics resources e.g. vehicles, platform, software tool. Generally, in the logistics pooling investigation, we divide pooling collaborations into four categories (listed in Table II) with respect to different collaboration preferences and coordination cost e.g. communication costs, investment in IT [40]. These factors impact the potential sub-coalition decisionmaking scheme and thus should be considered in modeling process. As coordination costs are negligible groups grows by joining new members and the corresponding cooperative game is super-additive. As coordination costs increase, the games becomes non-super-additive.

From now on, we focus on situation when independent business organizations arrange pooling collaborations among them to minimize their individual costs with individual optimum preferences $\left(C_{4}\right.$ case in Table II). In this case, a collaboration scheme based on sub-coalition (with sub-groups of participants) seems to be optimal and preferable. A natural question arises: "Which coalitions can be expected to be formed?" Our objective is to give an answer to this question. By applying PC, we decide which sub-coalition will be optimal for the alliances of company. The following three steps have been used.

Step 1.Completion of the pairwise comparisons matrix. To achieve an efficient collaboration by our model, the first step is to select all possible subsets of the members in a group of companies. For $n$ members it would lead us to $2^{n}-n-1$ sub-coalition, which are 
TABLE I

MOTIVES FOR HORIZONTAL COOPERATION IN LOGISTICS CONTEXT [9]

\begin{tabular}{|l|l|l|l|}
\hline Cost and productivity & Customer service & Market position & Other \\
\hline - Cost reduction & - Complementary goods and services & - Penetrating new markets & - Developing technical standards \\
- Learning and internalization of tacit, & - Ability to comply to strict customer & - New products development & - Accessing superior technology \\
collective and embedded knowledge & requirements/improved service & - Serving larger firms & - Overcoming legal/regulatory \\
- More skills labour force & - Specialization & - Protecting market share & barriers \\
& & - Faster speed to market & - Enhancing public image \\
\hline
\end{tabular}

TABLE II

SELECTED CATEGORIES OF POOLING CASES [40].

\begin{tabular}{|l|l|l|}
\hline Coordination cost & Global optimum & Individual optimum \\
\hline Negligible & $\begin{array}{l}C_{1}: \text { super-additive collaboration } \\
\text { with global optimum preferences }\end{array}$ & $\begin{array}{l}C_{2}: \text { super-additive collaboration } \\
\text { with individual optimum preferences }\end{array}$ \\
\hline Significant & $\begin{array}{l}C_{3}: \text { non-super-additive } \\
\text { collaboration with global optimum preferences }\end{array}$ & $\begin{array}{l}C_{4}: \text { non-super-additive } \\
\text { collaboration with individual optimum preferences }\end{array}$ \\
\hline
\end{tabular}

non-empty and non-singletons. Next, each company evaluates two criteria connected with possible structure of coalition in term of their relative importance. Index value from 1 to 4 (and its inverse $1 / 4$ to 1) are used and entered row by row into a crossmatrix. All gradations are possible in between. Each pairwise comparisons $a_{i j} \in[1 / 4,4]$ represents the scaled relative importance scores of element $i$ as compared to element $j$. In practice, values below the main diagonal do not need to be entered, since they are reciprocal to the corresponding values in the upper triangle. As a result, we get a pairwise comparisons matrix of size $m \times m$, where $m$ denotes the number of items to compare. Formally, for $n$ business organization $m=2^{n-1}-1$.

Step 2.Calculating the criteria weight. Once the firms provide all the $m(m-1) / 2$ comparisons, the goal is to find a positive weight vector $w=\left[w_{1}, \ldots w_{m}\right] \in$ $R^{m}$ such that the pairwise ratio of the weights, $w_{i} / w_{j}$ are as close as possible to the matrix elements $a_{i j}, 1 \leq i, j \leq m$. For this purpose, we use the geometric means (GM) method.

Step 3.Collaboration decision. In this step, collaborators try to establish the structure of the coalition. This coalition for which the mean value is highest, is the most preferable for all potential partners and as a result successful collaborations groups should be established. However, in practice, there are two possibilities for this step: an agreement is achieved (collaboration relationship is established) or individual members of group deviate, the others move back to Step 1.

By constructing a PC matrix, we are able to identify the most desirable coalition for business organizations with individual preferences expressing incentives to collaborate. Following this collaboration process and specifying the technical details, this study provides a solution to horizontally cooperating companies who are reluctant to share sensitive information and want to avoid making excessive communications.

\section{RESULTS AND ANALYSIS}

In this Section, we use a numerical example to apply presented PC method to determined alliance formation among independent business organizations, which have significance motivation to cooperate. This motivation has been frequently associated with the following drivers of horizontal collaboration: cost reduction, service improvement, market position, skill and knowledge sharing, investment and risk sharing, emission reduction, congestion reduction [40] as well as protect environment and mitigate climate change [35].

Let suppose we have a group of three companies (labeled $\left.X_{1}, X_{2}, X_{3}\right)$, then we separate candidate into possible collaboration groups (which are non-empty and non-singleton), namely:

$$
\left\{X_{1}, X_{2}\right\},\left\{X_{1}, X_{3}\right\},\left\{X_{2}, X_{3}\right\},\left\{X_{1}, X_{2}, X_{3}\right\}
$$

In our case, each company based on their individual satisfaction (connected with drivers of horizontal collaboration) has to fill one pairwise comparisons matrix. Every business organization needed to determine 3 ratios: $m_{12}, m_{13}, m_{23}$, which are the part of following matrix:

$$
M=\left[\begin{array}{ccc}
1 & m_{12} & m_{13} \\
\frac{1}{m_{12}} & 1 & m_{23} \\
\frac{1}{m_{13}} & \frac{1}{m_{23}} & 1
\end{array}\right]
$$

This step is the most complicated and should consist of some technical tools to design efficient method for filling the matrix. In each matrix on the main diagonal, we have number 1 due to the fact that it represents a relative ratio of a criterion against itself. All three PC matrixes are obtained and presented in Table III.

After each business organization sets its preference of alliance with other partners, the PC matrix is constructed and weights are computed as the geometric means of rows; 
TABLE III

PAIRWISE COMPARISONS MATRIX FOR EACH COMPANY.

\begin{tabular}{|c|c|c|c|}
\hline \multicolumn{4}{|c|}{ Company $X_{1}$ preferences } \\
\hline & $\left\{X_{1}, X_{2}\right\}$ & $\left\{X_{1}, X_{3}\right\}$ & $\left\{X_{1}, X_{2}, X_{3}\right\}$ \\
\hline$\left\{X_{1}, X_{2}\right\}$ & 1 & 1,5 & 3 \\
\hline$\left\{X_{1}, X_{3}\right\}$ & 0,67 & 1 & 3,6 \\
\hline$\left\{X_{1}, X_{2}, X_{3}\right\}$ & 0,33 & 0,28 & 1 \\
\hline \multicolumn{4}{|c|}{ Company $X_{2}$ preferences } \\
\hline & $\left\{X_{1}, X_{2}\right\}$ & $\left\{X_{2}, X_{3}\right\}$ & $\left\{X_{1}, X_{2}, X_{3}\right\}$ \\
\hline$\left\{X_{1}, X_{2}\right\}$ & 1 & 2 & 2 \\
\hline$\left\{X_{2}, X_{3}\right\}$ & 0,5 & 1 & 2 \\
\hline$\left\{X_{1}, X_{2}, X_{3}\right\}$ & 0,5 & 0,5 & 1 \\
\hline \multicolumn{4}{|c|}{ Company $X_{3}$ preferences } \\
\hline & $\left\{X_{1}, X_{3}\right\}$ & $\left\{X_{2}, X_{3}\right\}$ & $\left\{X_{1}, X_{2}, X_{3}\right\}$ \\
\hline$\left\{X_{1}, X_{2}\right\}$ & 1 & 2,5 & 1,3 \\
\hline$\left\{X_{2}, X_{3}\right\}$ & 0,4 & 1 & 4 \\
\hline$\left\{X_{1}, X_{2}, X_{3}\right\}$ & 0,77 & 0,25 & 1 \\
\hline
\end{tabular}

the weights of their coalitions structure were calculated using Concluder [8].

TABLE IV

Weight EVALUATION BASED ON PAIRWISE COMPARISONS.

\begin{tabular}{|c|c|c|c|c|}
\hline & $\left\{X_{1}, X_{2}\right\}$ & $\left\{X_{1}, X_{3}\right\}$ & $\left\{X_{2}, X_{3}\right\}$ & $\left\{X_{1}, X_{2}, X_{3}\right\}$ \\
\hline$X_{1}$ & 0,48 & 0,39 & 0 & 0,13 \\
$X_{2}$ & 0,49 & 0 & 0,31 & 0,2 \\
$X_{3}$ & 0 & 0,46 & 0,36 & 0,18 \\
\hline Average & 0,32 & 0,28 & 0,22 & 0,17 \\
\hline
\end{tabular}

In each row, there is one 0 value. It refers to the situation when a company does not have incentive to create a coalition with itself. Next, based on the results, a suitable coalition structure is constructed. It is supported by PC as a guidance tool for building coalitions. In the represented case, the highest preferences have been assigned to $\left\{X_{1}, X_{2}\right\}$, while on the second place we have $\left\{X_{1}, X_{3}\right\}$ coalition, and the least profitable sub-coalition is a grand coalition $\left\{X_{1}, X_{2}, X_{3}\right\}$.

\section{NUMBER OF COMPARISONS}

The case study indicates that our model is attractive for smaller numbers of companies from 3 up 5 . From a practical point of view, the number of comparisons that should be made by one company is easy to handle. For bigger number of potential partners $(n \geq 6)$, the comparisons are increasing exponentially. In Table $\mathrm{V}$ we see that for 7 companies, number of comparisons that should be made by one partner is 1953 .

Table V shows that exponential growth does not cause comparisons increases for up 5 business organizations. Generally, when we have $n$ company, the number of needed comparisons are presented in Table VI.

\section{CONCLUSIONS AND FUTURE RESEARCH}

This study has demonstrated that using pairwise comparisons, as a framework to model cooperation in logistics, can produce valuable results. We have demonstrated in this study that pairwise comparisons can be effectively used for formation of coalitions when the coalition forming solutions follow the satisficing principle introduced by Herbert A. Simon in 1956 and well described in [39].

What is more important that this study initiates a new direction of research in important logistics problems. One of them is the open problem of the bargaining power of collaborative members in business negotiations. In current logistics practice, we observe that a person, group, or organization has ability to enforce their preferences. Such bargaining power is closely related to influence, financial and organizational power, size or status of the collaborators. The bargaining power directly influences the potential group decision. It should be considered in the alliance formation process.

Another research direction worth pursuing on coalition formation by PC is the characterization of the complementary coalition. The complementary coalition is the coalition of the company that is not included in the primary coalition, e.g. we have 5 business organizations that want to use the proposed method. By it, we find that coalition $X_{2}, X_{5}$ is near optimal coalition structure. What would be now the complementary coalition from the set $X_{1}, X_{3}, X_{4}$ ? The third research direction is to investigate the coalition structure with some additional constraints. For instance, the number of coalition members in a coalition could be limited to $k, 2 \leq k \leq n$. The question now is how to form and search for such coalition structure. These issues are subject for our future research.

\section{ACKNOWLEDGMENT}

The authors are grateful to Grant O. Duncan (Team Lead, Business Intelligence and Software Integration, Health Sciences North, Sudbury, Ontario) and Tyler Jessup, Laurentian University, for their help with proofreading this text and development of the software system based on the presented theory.

\section{REFERENCES}

[1] Agarwal, R.; Ergun, Ö., Network design and allocation mechanisms for carriere alliances in liner shipping, Operations Research, 58(6); 1726 1742, 2010.

[2] Alqarni, M.; Y. Arabi, Y.; Kakiashvili, T.; Khedr, M.; Koczkodaj, W.W.; Leszek, J.; Przelaskowski, A.; Rutkowski, K., Improving the predictability of ICU illness severity scales, Federated Conference on Computer Science and Information Systems (FedCSIS), Szczecin, IEEE Conference Publications, 11 - 17, 2011.

[3] Arrow, K.J., A Difficulty in the Concept of Social Welfare, Journal of Political Economy, 58(4): 328-34, 1950.

[4] Audy, J.F.; D'Amours, S.; Rönnqvist, M., An empirical study on coalition formation and cost/savings allocation, International Journal of Production Economics, 136(1): 13 - 27, 2012.

[5] Aumann, R.J.; Myerson, R. B., Endogenous formation of links between players of coalitions: an application of Shapley value, University Press, Cambridge, 175-191, 1988.

[6] Babiy, V.; Janicki, R.; Wassyng, A.; Bogobowicz, A.D.; Koczkodaj, W.W., Selecting the best strategy in a software certification process, Federated Conference on Computer Science and Information Systems (FedCSIS): 53 - 58, 2010.

[7] Condorcet, M., The Essay on the Application of Analysis to the Probability of Majority Decisions, Paris: Imprimerie Royale, 1785

[8] Concluder, https : //sourceforge.net/projects/concluder/, accessed 2016-05-01. 
TABLE V

NUMBER OF COMPARISONS

\begin{tabular}{|c|c|c|c|c|c|}
\hline $\begin{array}{c}\text { Number } \\
\text { of company }\end{array}$ & $\begin{array}{c}\text { Possible } \\
\text { sub-coalition }\end{array}$ & $\begin{array}{c}\text { Number } \\
\text { of PCM }\end{array}$ & $\begin{array}{c}\text { Dimension } \\
\text { of PCM }\end{array}$ & $\begin{array}{c}\text { Comparisons } \\
\text { in one PCM }\end{array}$ & $\begin{array}{c}\text { Total number } \\
\text { of comparisons }\end{array}$ \\
\hline 3 & 4 & 3 & 3 & 3 & 9 \\
4 & 11 & 4 & 7 & 21 & 84 \\
5 & 26 & 5 & 15 & 105 & 525 \\
6 & 57 & 6 & 31 & 465 & 2790 \\
7 & 120 & 7 & 63 & 1953 & 13671 \\
8 & 247 & 8 & 127 & 8001 & 64008 \\
9 & 502 & 9 & 255 & 32385 & 291465 \\
10 & 1013 & 10 & 511 & 130305 & 1303050 \\
\hline
\end{tabular}

TABLE VI

FORMULAS FOR NUMBER OF COMPARISONS.

\begin{tabular}{|ll|}
\hline$n$ & - number of companies, \\
$2^{n}-n-1$ & - number of all possible sub-coalitions, \\
$2^{n-1}-1$ & - dimension of one PCM, \\
$\left(2^{n-1}-1\right)\left(2^{n-2}-1\right)$ & - number of comparisons in one PCM, \\
$n\left(2^{n-1}-1\right)\left(2^{n-2}-1\right)$ & - total number of comparisons, \\
\hline
\end{tabular}

[9] Cruijssen, F., Horizontal Cooperation in Transport and Logistics, Dissertation thesis, University of Tilburg, 2007.

[10] Cruijssen, F.; Dullaert, W.; Fleuren, H., Horizontal cooperation in transport and logistics: A literature review, Transportation Journal, 207 (3): 22 - 39, 2007

[11] Dai, B.; Chen, H., A multi-agent and auction-based framework and approch for carrier collaboration, Logistics Research, 3: 101 - 120, 2011.

[12] Faliszewski, P.; Hemaspaandra, E.; Hemaspaandra, L. A., Using Complexity to Protect Elections, Communications of the ACM, 53(11): 7482, 2010.

[13] Fang, X.; Cho, S.-H., Stability and endogenous formation of inventory transshipment networks, Operations Research, 62(6): 1316 - 1334, 2014.

[14] Fechner, G., Elemente der Psychophysik, 1860.

[15] Frisk, M.; Göthe-Lundgren, M.; Jörnsten, K.; Rönnqvist, M., Cost allocation in collaborative forest transportation, European Journal of Operational Research, 205: 448 - 458, 2010.

[16] Guajardo, M.; Rönnqvist, M, Operations research models for coalition structure in collaborative logistics, European Journal of Operational Research, 240(1), 147 - 159, 2015

[17] Kahan, J.P.; Rapoport, A., Theories of coalition formation, Lawrence Erlbaum Associates, 1984

[18] Kakiashvili, K.; Koczkodaj, W.W.; Phyllis Montgomery, P.; Passi, K.; Tadeusiewicz, R., Assessing the Properties of the World Health OrganizationŠs Quality of Life Index, Federated Conference on Computer Science and Information Systems (FedCSIS), Wisla, IEEE Conference Publications, 151 - 154, 2008.

[19] Kefi, M.; Ghedire, K., A multi-agent model for the Vehicle Routing Problem with Time Windows, WIT Transactions on The Built Environment, 75, 2004.

[20] Kemahlioglu-Ziya, E.; Bartholdi III, J.J., Centralizing inventory in supply chain by using Shapley value to allocate the profits, Manufacturing \& Service Operations Management, 13(2), 146-162, 2011.

[21] Koczkodaj, W.W., Mikhailov, L., Redlarski, G., Soltys, M., Szybowski, J., Tamazian, G., Wajch, E., Yuen, K.K.F., Important Facts and Observations about Pairwise Comparisons, Fundamenta Informaticae, 144: 1-17, (2016)

[22] Krajewska, M.; Kopfer, H.; Laporte, G.; Ropke, S.; Zaccour, G., Horizontal cooperation among freight carriers: request allocation and profit sharing, Journal of the Operational Research Society, 59: 1483 - 1491, 2008

[23] Lozano, S.; Moreno, P.; Adenso-Díaz, B.; Algabaí, E., Cooperative game theory approach to allocating benefits of horizontal cooperation, European Journal of Operational Research, 229: 444 - 452, 2013.

[24] Luce, R.D.; Raiffa, H., Games decisions, John Wiley \& Sons, New York, 1957

[25] Myerson, R.B., Game theory: analysis of conflict, Harvard Unversity Press, 1991.

[26] G. Owen, Game theory, London, UK: Academic Press, Oct. 1995.

[27] Özener, O., Developing a collaborative planning framework for sustainable transportation, Mathematical Problems in Engineering, art. ID 107102, 2014

[28] Özener, O.; Ergun, Ö., Allocationg costs in a collaborative transportation procurement network, Transportation Science, 42: 146 - 165, 2008.

[29] Perea, F.; Puerto, J.; Fernández, F.; Modeling cooperative on a class of distribution problems, European Journal of Operational Research, 198: 726 - 733, 2009

[30] Rapoport, A.; Kahan, J.P.; Funk, S.G.; Horowitz, A.D., Coalition formation by sophisticated players, Springer, 1979.

[31] Saad, W.; Han, Z.; Basar, T.; Debbah, M.; Hjorungnes, A., Hedonic coalition formation for distributed task allocation among wireless agents, IEEE Transactions on Mobile Computing, 10(9), 1327 - 1344, 2011.

[32] Saaty, T.L., A scaling method for priorities in hierarchical structures, Journal of Mathematical Psychology, 15: 234-281, 1977.

[33] Sandholm, T.; Larson, K.; Anderson, M.; Shehory, O.; Tohme, F., Antytime coalition structure generation with worst case guarantees, Proceedings of the Fifteenth National Conference on Artifical Intelligence, $46-53,1998$.

[34] Sandholm, T.; Lesser, V.R., Coalitions among computationally bounded agents, Artifical Intelligence, 94: 99 - 137, 1997.

[35] Simchi-Levi, D.; Simchi-Levi, E.; Kaminsky, P., Designing and managing the supply chain: concepts, strategies, and cases, New-York: McGraw-Hill, 1999.

[36] Thurstone, L.L., A law of comparative judgement, Psychological Review, 34: 278-286, 1927.

[37] Ulrike, L. - W., Pauoff divisions on coalition formation in a three-person characteristic function experiment, Journal of Economic Behavior \& Organization, 17(1): 183 - 193, 1992.

[38] Wi, H.; Oh, S.; Mun, J.; Jung, M., A team formation model based on knowledge and collaboration, Expert Systems with Applications, 36(5): 9121 - 9124, 2009.

[39] Winter, S.G., The satisficing principle in capability learning, Startegic Management Journal, 21(10 - 11): 981 - 996, 2000.

[40] Xu, X., Collaboration mechanism in the horizontal logistics collaboration, Dissertation thesis, 2014.

[41] Zlotkin, G.; Rosenschein, J.S., Coalition, cryptography, and stability: Mechanism for coalition formation in task oriented domains, AAAI, 432: 87 - 94, 1994 